\title{
¿De Hendaya a San Francisco? Londres y Washington contra Franco y la Falange (1942-1945)
}

\author{
Carlos Collado Seidel
}

Seguramente ningún analista de la situación política en julio de 1941 hubiera dado crédito a un augurio que hubiera pronosticado que, aunque Hitler finalmente se suicidaría en un bunker y Mussolini sería muerto a tiros por partisanos, Franco, sin embargo, no sólo sobreviviría a la derrota del Eje, sino que también permanecería el régimen por él establecido.

El régimen español era visto en un contexto indisoluble con el fascismo y el nacionalsocialismo; era el resultado de la época fascista en Europa; y, si bien hubiera sido posible hacer referencia a analogías existentes entre el régimen de Franco y el de Salazar en Portugal o el de Getulio Vargas en el Brasil, éstos no tenían el estigma del pecado original de haber alcanzado el poder merced a la ayuda de Hitler y Mussolini. Para la opinión pública internacional, el fascismo y el falangismo eran sinónimos, y Franco era parangonado con los dictadores italiano y alemán.

La adhesión al Pacto Anticomintern, la entrevista de Hitler con Franco en Hendaya, la declaración de no-beligerancia, todo esto eran hitos de la implícita alianza entre Franco y los regímenes del Eje. Esta se hizo harto patente en julio de 1941 cuando Franco, bajo la impresión del comienzo de la guerra con la Unión Soviética, declaró en público su confraternización con las armas alemanas y resaltó la unidad de destino de España y de los países del Eje: «La suerte ya está echada. En nuestros campos se dieron y ganaron las primeras batallas... Las armas alemanas dirigen la batalla que Europa y el Cristianismo desde hace tantos años anhelaban, y en la que la sangre de nuestra juventud va a unirse con la de nuestros camaradas del Eje, como expresión viva de solidaridad" 1.

Bulletin of Spanish Studies, vol. XVIII, Nr. 72, octubre de 1941, pp. 210-217. 


\section{1. ¿EL PALO O LA ZANAHORIA? BRITANICOS Y \\ NORTEAMERICANOS ANTE LA POLITICA ESPAÑOLA}

España había adquirido después de la capitulación de Francia una gran importancia para ambos bandos beligerantes. Con su ubicación estratégica, su Protectorado en Marruecos y sus archipiélagos, representaba ser la llave para el acceso al Mediterráneo occidental. Londres dependía largamente de una España no hostil para garantizar la seguridad en su fortaleza de Gibraltar y poder mantener su ruta de aprovisionamiento a través del Mediterráneo. La designación de Sir Samuel Hoare, un peso pesado de la política inglesa, como Embajador de la Gran Bretaña en Madrid, demuestra la gran importancia que para Londres tenía la situación en la Península Ibérica. En estos primeros años de la guerra, la diplomacia inglesa no se hacia ilusión alguna de lograr que la España de Franco se sumara al bando aliado; la política anglosajona apuntaba a evitar precisamente lo contrario, que Franco entrara en la guerra al lado del Eje ${ }^{2}$. Este cometido lo perseguiría Londres especialmente a base de la "zanahoria" de un programa económico, que proveeria España de productos básicos (derivados del petróleo, caucho, algodón) para garantizar al menos un mínimo funcionamiento de la economía española, productos que Alemania, por su parte, no podía o no quería suministrar.

Aparte de su importancia estratégica, España también era de gran interés económico para la industria de guerra británica, que se proveía en este pais de una considerable cantidad de productos y materias primas, especialmente potasa, pirita y mineral de hierro, que no queria arriesgarse a perder. La ventaja que en este caso ofrecía abastecerse de productos españoles, era por un lado, sin duda alguna, el corto trayecto para transportar los productos, y por otro la circunstancia de que sólo difícilmente podian ser éstos reemplazados por otros de proveniencia aliada. Además hacía falta una España más o menos asequible para poder efectuar las denominadas compras preventivas de productos de interés estratégico para Alemania como el wolframio, o pieles y tejidos de lana.

En Washington, sin embargo, se adoptaría una actitud que diferiría básicamente de la perspectiva británica y llevaría más de una vez a serios momentos de fricción con la política británica. Con la entrada de los Estados Unidos en la guerra, se inaugurarian interminables debates

\footnotetext{
El mejor análisis de la politica británica respecto de España en estos años lo sigue siendo: Denis Smyth: Diplomacy and strategy of survival: British policy and Franco's Spain, 1940-41, Cambridge (University Press) 1986.
} 
acerca de la forma de utilizar el suministro de petróleo por parte de los Aliados como arma para perseguir fines estratégicos en España.

En la opinión pública norteamericana e incluso en determinados sectores del Departamento de Estado, la guerra civil española estaba considerablemente más presente que en Inglaterra. Además, allí se procedía de forma menos diferenciada a analizar el régimen franquista, dominando la opinión general de que España entraría en la guerra de parte del Eje en el momento en que pareciera vislumbrarse la victoria de Alemania. El Departamento de Estado norteamericano, en todo caso, quería evitar toda impresión de ayudar abiertamente al dictador español por medio de envíos de productos y materias primas que, como el petróleo o el caucho, eran incluso de interés estratégico. El Secretario de Estado Cordell Hull intentaría siempre evitar dar la impresión de tratar de apaciguar a Franco ${ }^{3}$.

$\mathrm{Y}$, aun tratándose de un programa de suministro anglo-americano conjunto, al proceder el carburante destinado a España de refinerías caribeñas controladas por Washington, la administración norteamericana no veía inconveniente alguno en cortar ese suministro (incluso sin consultar previamente a los ingleses), si razones de política interior u otras parecian recomendar el cese de tales envíos. Desde el punto de vista norteamericano, el petróleo era una baza importante en el trato con España, que podía ser jugada para forzar a Franco a realizar una determinada política o para conseguir de él ciertas concesiones. Para Londres, sin embargo, cortar el suministro de petróleo era únicamente la ultima ratio en el trato con el régimen de Franco. Por tanto, mientras que Londres abogaba por una política mesurada con la cual ganar la confianza del dictador, el Departamento de Estado veía precisamente en la prosecución de una línea inflexible y de claras exigencias la forma ideal de tratar con Franco. No cabe duda de que Washington estaba contrariando de esta forma los proyectos Iondinenses respecto de España. Estas divergencias tenian sin duda alguna su origen en una diferente percepción de la nación española. El error norteamericano, según los comentarios críticos de Londres, se basaba en que, aun siendo España un país débil y se aceptara o no el régimen imperante, tenía una vieja cultura y un pronunciado orgullo nacional, por lo que debía ser tratada con más tacto que el conjunto de repúblicas centroamericanas. Estas

3 Cfr. sus memorias: The Memoirs of Cordell Hull, London (Hodder \& Stoughton), 1948, pp. 1.188 ss y 1.326 ss. 
discrepancias llevarian repetidamente a desacuerdos e incluso a graves conflictos entre ambos gobiernos.

Mientras que la situación en los campos de batalla siguiera siendo adversa a los Aliados, Londres no veia la posibilidad de ejercer mayor presión sobre Madrid para obtener determinadas ventajas de tipo político o económico, o para lograr que España se distanciara claramente de Alemania y pusiera por ejemplo fin al espionaje alemán en España 0 al aprovisionamiento de submarinos alemanes desde las costas españolas.

El éxito de la Operación Antorcha en noviembre de 1942 supuso ofrecer una nueva perspectiva en este sentido dentro de la política anglo-americana hacia España. Con los avances de las tropas aliadas en el norte de Africa comenzó a madurar la convicción de que Alemania no tenía que ganar forzosamente la guerra, y Franco, por consiguiente, comenzó a ser más accesible a los deseos de ingleses y norteamericanos.

El régimen consintió que los pilotos de las fuerzas aéreas aliadas se evadieran de sus lugares de internamiento y salieran del país vía Gibraltar; permitió asímismo el tránsito por España de franceses que deseaban evadirse a la denominada France Libre en Argelia: hasta finales de 1943, y no obstante las protestas de Berlín, atravesaron de esta forma la Península Ibérica unos 20.000 franceses para alistarse en el ejército de De Gaulle; en junio de 1943 se establecieron relaciones oficiosas entre Argel y Madrid; incluso en el sector de la propaganda se comenzaron a notar ciertos cambios alentadores para los Aliados.

La destitución de Mussolini en julio de 1943 resultó ser un golpe más contra la altivez germanófila. Y si hasta entonces, la diplomacia británica y con ella la norteamericana habian considerado que todavia no era el tiempo de exigir más enérgicamente un cambio sustancial de actitud, tal parecer cambiaría a partir del verano de 1943. A Franco, que hasta entonces podía haber tenido la impresión de ser cortejado por los Aliados, había que hacerle comprender que ni Londres ni Washington estaban en modo alguno conformes con su rumbo en política exterior.

Si hasta el momento había tenido vigencia la política de asegurar la neutralidad española por medio de ayudas económicas, las victorias en los campos de batalla debian redundar necesariamente en una mayor amplitud de posibilidades de maniobra de los Aliados, quienes de este modo podían exigir más que la mera neutralidad de España en el conflicto. Después de la campaña de Túnez, el Embajador norteamericano en 
Madrid escribiria a Washington: «no basta con pensar en una estricta neutralidad española. Se trata de hacer que su neutralidad sea «benevolente» hacia nosotros, que sus recursos (minerales, fábricas y navegación) sean empleados para la causa aliada y se nieguen al Eje" ${ }^{4}$. Ahora, tanto Londres como Washington comenzarian a exigir concesiones sustanciales a su favor.

No obstante, Londres ni siquiera ante estas nuevas perspectivas pensaba en pasar de la política de la zanahoria a la del palo. En las cancillerías británicas se pensaba que una política de creciente aunque mesurada presión diplomática daría los frutos deseados. En este sentido intentaría Londres convencer a Washington de la conveniencia de esta nueva táctica sin cambiar de estrategia.

Aunque la administración norteamericana nunca acabó de convencerse de la utilidad de esta política, plegándose a la política diseñada en Londres por la conveniencia de mantener un frente común, tanto Hayes como su colega británico comenzaron una nueva etapa de demandas concretas al régimen de Franco, exigiendo entre otros asuntos la retirada de la División Azul del frente de Rusia. En julio de 1943 entregaría Hoare a Jordana un extenso memorándum en el que se detallaban todas las reclamaciones que la diplomacia británica hacía a España y que sería tema de una entrevista de Hoare con Franco en el Pazo de Meirás el 20 de agosto de $1943^{5}$. El objetivo que el Embajador británico se proponía alcanzar de Franco era, según su testimonio, hacerle dudar de su propia opinión poniéndole en vías de una neutralidad auténtica.

Esta nueva política pareció dar sus primeros frutos al resolverse ciertos asuntos secundarios en sentido favorable para los Aliados. Jordana incluso comenzó a preparar la retirada de la División Azul, y ello a pesar de una fuerte oposición dentro del Consejo de Ministros.

En Londres se constataba con franca satisfacción este aparente cambio de política en España, así como la creciente benevolencia del régimen español respecto de los Aliados. Pero para desgracia de Jordana, los Aliados, y pese a su satisfacción por ver resuelta alguna de sus demandas, en vez de disminuir su presión sobre el régimen, siguieron incrementándola, añadiendo nuevas reclamaciones, como por ejemplo la clausura del consulado general del Reich en Tánger o la liberación de los barcos

\footnotetext{
4 Citado en Carlton J.H. Hayes: Misión de guerra en España, Madrid (Epesa) 1946, p. 176.

5 El texto aparece reproducido integramente en Samuel Hoare (Viscount Templewood), Ambassador on Special Mission, London (Collins) 1946, pp. 197-204.
} 
mercantes y de guerra italianos retenidos en puertos españoles. "Contrasta esta actitud nuestra con la del Gobierno británico", se lamentaba el titular de Exteriores ante el Embajador de Londres, "que aparece más exigente cuantas mayores concesiones se le hacen" ${ }^{6}$.

Poco a poco se iban desenmascarando las verdaderas intenciones de los Aliados. A comienzos de noviembre de 1943 decía Hoare a Jordana: "Sin pretender ingerirme en la política del Gobierno español, me permito indicar si no ha llegado ya el momento en que éste, viendo el curso de la guerra, se decida a colaborar con el grupo de Naciones que va a resultar triunfante en la misma" " . Una primera advertencia clara del representante británico al Gobierno español.

No obstante la evolución alentadora de aquellos últimos meses, la política anglo-americana con respecto a España se vio de nuevo gravemente perturbada como consecuencia del «Affaire Laurel». El envio de un telegrama al Presidente del Gobierno títere de Filipinas por parte del Gobierno español brindó a los sectores anti-franquistas del State Department una ocasión excelente para volver a cuestionar la política aliada con España ${ }^{8}$. Sin haber consultado de antemano al Foreign Office, y suponiendo que la situación estratégica ya no obligaba a emplear una política "blanda» respecto de España, debido a lo cual tampoco era preciso continuar a toda costa la ayuda económica al régimen, el State Department, respaldado por una resolución tomada por los Joint Chiefs of Staff durante la Conferencia de Quebec se decidió a endurecer la política hacia España, y a presionar seriamente para conseguir el cese definitivo de la ininterrumpida ayuda española a Alemania, en especial de los envíos de wolframio, materia prima indispensable para la industria de armamentos alemana, que en el marco de las compras preventivas aliadas consumia enormes sumas de dinero ${ }^{9}$.

\footnotetext{
6 Protocolo de una entrevista entre Hoare y Jordana, 4. 11. 1943, Archivo del Ministerio de Asuntos Exteriores (AMAE), R-4294/16.

7 Protocolo de una entrevista entre Hoare y Jordana, 4. 11. 1943, AMAE, R-4.294/16.

8 El texto del telegrama está reproducido en José Maria Doussinague: España tenia razón (1939-1945), Madrid (Espasa-Calpe) 1950, p. 282. Cfr. además Frus, 1943, II, pp. 723-731; James W. Cortada: Relaciones España-USA, 1941-45, Barcelona (Dopesa), 1973, pp. 45-52.

9 Telegrama de Stettinius a Hayes, 6. 11. 1943, Frus, 1943, I1. p. 649; Luis Suárez Fernández: Francisco Franco y su tiempo, Madrid (Fundación Nacional Francisco Franco) 1984, vol. III, pp. $466 \mathrm{~s}$.
} 
$Y$ aunque finalmente el Foreign Office y el propio Embajador norteamericano en Madrid lograron que Washington desistiera de sus propósitos, y no intentara explotar más el incidente Laurel, no pasaría mucho tiempo hasta que el Departamento de Estado volviera a la carga y provocara no sólo la más grave crisis en las relaciones de los Aliados con España durante la guerra mundial, sino también en las relaciones entre Washington y Londres.

Si bien el Foreign Office quería obtener mayores concesiones por medio de gestiones diplomáticas, estaba no obstante convencido de que los españoles nunca accederian a un embargo total de los envíos de wolframio a Alemania, aun utilizando el arma económica, y por ello rehusaba revisar a fondo su poítica española. Londres no quería en modo alguno complicaciones con España, sino que por el contrario deseaba mantener una situación tranquila en la Península Ibérica. En esto, claro está, influyen tanto la importancia de España para la seguridad del tráfico naviero a través del Estrecho como la relevancia de los envíos de materias primas españolas para la industria y comercio británicos. Londres estaría dispuesta a defender estos intereses - que no sólo estaban ligados a los acontecimientos de la guerra - incluso arriesgándose a una grave crisis con el Gobierno de Washington.

Nuevamente sin previa consulta en Londres, el Embajador norteamericano entregó el 18 de noviembre de 1943 en el Palacio de Santa Cruz un memorándum en que el Gobierno de Washington exigía el cese incondicional de la exportación española de wolframio ${ }^{10}$. $Y$ al pasar semana tras semana sin obtener una respuesta, los norteamericanos decidieron una vez más utilizar el arma del petróleo para obligar al Gobierno de Madrid a tomar una decisión favorable a los Aliados.

La cuestión del wolframio había adquirido, además, una importancia adicional con la concesión por parte española de un amplio crédito financiero de 100 millones de marcos a los alemanes para efectuar compras de materias estratégicas, y especialmente de wolframio, en España ${ }^{11}$. Esta circunstancia pesaba tanto más cuanto que, en el verano de 1943, los Aliados habian finalmente logrado controlar el mercado de wolframio, debido a la escasez crónica de divisas que padecía la economía del Reich, y no estaban dispuestos a recomenzar la "guerra» del wolframio invirtiendo mayores cantidades aún

10 Memorándum de la Embajada de EE.UU. al Gobierno español, 18. 11. 1943, AMAE, R4.294/17.

11 Cfr. Rafael Garcia Pérez: Franquismo y Tercer Reich. Las relaciones hispano-alemanas durante la Segunda Guerra Mundial, Madrid (Centro de Estudios Constitucionales) 1994. 
de dinero para realizar las compras preventivas de este material. La cuestión del wolframio - y así también lo veía Londres- no podía ser resuelta únicamente a nivel económico, sino que era en primer lugar una cuestión política. La situación en los campos de batalla tenía, pues, que repercutir necesariamente en el tema del wolframio a favor de los Aliados.

Finalmente, los Gobiernos de Estados Unidos y Gran Bretaña concertaron una escalada gradual de las medidas a tomar contra Madrid. Mientras que, por un lado, se diría a Franco que por razones de la intensificación de la guerra, y por tanto de un aumento de consumo propio, se habia tenido que acordar la suspensión de los suministros de gasolina previstos para febrero de 1944, por otro lado, pero de forma independiente, evitando una conexión explícita entre ambos asuntos, se exigiría la suspensión de determinadas medidas antialiadas (espionaje y sabotaje, wolframio, etc.), dejando por tanto a los españoles que ellos mismos sacasen las conclusiones correspondientes.

Pero, debido a una indiscreción por parte del Departamento de Estado, al hacerse al poco tiempo públicas las intenciones de los Aliados, no sólo no se cumplió el procedimiento acordado, sino que los norteamericanos ni siquiera se mostraron ahora interesados en alcanzar una rápida solución de la crisis mediante un resultado negociado entre Madrid, Washington y Londres.

Esto quedó patente al vislumbrarse una posible base de acuerdo entre Jordana y Hoare para resolver los problemas pendientes y en especial el asunto más espinoso: el del wolframio. Según este proyecto de compromiso se congelarian las exportaciones de wolframio a Alemania al bajo nivel del año 1943, mas, aunque tanto el Foreign Office como el propio Embajador norteamericano en Madrid consideraban esta fórmula como muy ventajosa y recomendaban su aceptación, sin embargo no fue posible convencer de lo mismo al Departamento de Estado. Este persistía en la exigencia de un embargo definitivo de las exportaciones de wolframio y rechazaba categóricamente la idea de un compromiso. Washington estaba convencido de que Franco, más pronto o más tarde, tendría que plegarse a las circunstancias. En el Departamento de Estado se tenía muy en cuenta, como precedente, el caso de Argentina, y se quería obligar a los neutrales a terminar con su política de indecisión ante el conflicto. Así Acheson decía a Halifax, el Embajador británico en Washington, que habia llegado el momento en que los neutrales tendrian que cumplir las exigencias de los Aliados, si éstos por su parte, se mantenian firmes en su política ${ }^{12}$. El

12 Telegrama de Halifax a Eden, 10. 2. 1944, Archivo del Foreign Office (FO) 371/39646. 
diplomático norteamericano no tenía la menor duda de que Franco capitularía de la misma forma que lo había hecho la Argentina.

Esta es, sin duda alguna, la principal razón que explica el largo período de negociaciones. Mas, dado que los españoles mantuvieron por largo tiempo de forma obstinada una posición inflexible frente a la presión ejercida por los Aliados (el Gobierno español se negaría a negociar una reducción de los envíos de wolframio mientras perduraran tanto el ultimátum aliado que exigía el cese definitivo de los envíos de wolframio a Alemania como el embargo de petróleo), en definitiva, las conversaciones entre Madrid y los representantes de los Aliados no pasaron de tener una importancia secundaria.

Ante la negativa de Washington a llegar a un resultado negociado (los Estados Unidos se encontraban en plena campaña pre-electoral) el Foreign Office y el State Department entablaron largas discusiones durante las cuales los británicos intentaron con insistencia hacer cambiar de opinión a los norteamericanos. Para el Foreign Office, la política de Washington llevaría necesariamente a una ruptura con el Gobierno de Madrid, en detrimento de los intereses británicos aqui. Aparte de sus intereses nacionales, Londres veía un buen número de razones que recomendaban una rápida solución del impasse: los alemanes llegarian a adueñarse de unas 700 toneladas de wolframio depositadas en almacenes cerca de la frontera con Francia; se pondrían en peligro todas aquellas concesiones que el Gobierno español ya había hecho en otros asuntos (consulado alemán en Tánger, División Azul, etc.); una España estabilizada era de gran interés estratégico ante las operaciones previstas en Francia; después del desembarco en el país galo mejoraría además para los Aliados la posición negociadora, y entonces se podrían alcanzar concesiones mucho más amplias. El peligro de tirar por la borda toda la política seguida respecto de España y los resultados adquiridos hasta entonces sólo por unas cuantas toneladas de wolframio parecía en Londres una alternativa ridícula. Además, caso de lograr una ruptura entre Madrid y Berlín, el Board of Trade veía graves problemas para abastecer a España de todos aquellos productos que estaba recibiendo de Alemania ${ }^{13}$.

En esta situación, y después de una serie de intentos fallidos por lograr que el State Department cambiara de opinión, se optó en Londres por pedir el apoyo de Churchill. Pero ni siquiera la mediación del Primer Ministro británico ante Roosevelt para urgir la aceptación de un compromiso dio el

13 Carta de Weich a Roberts, 20.3.1994, FO 371/39648. 
resultado esperado. La única concesión que después de varias semanas de discusiones parecía estar dispuesto a hacer el Departamento de Estado, fue no insistir en un embargo explícito del wolframio, siempre y cuando de facto no pasara más mineral la frontera con Francia. Incluso se mostraban dispuestos a endurecer más aún su política con España considerando la suspensión del envio de otros productos esenciales para la economía española, como el caucho o el algodón, aún arriesgando provocar con ello un caos en el interior.

A finales de marzo, después de dos meses de infructuosas negociaciones con Washington, el Gabinete de Guerra decidió una serie de medidas para hacer entrar a Washington en razón. Churchill volvería a enviar de nuevo a Roosevelt un telegrama apremiante; además, se proyectó pedir la ayuda tanto de los Combined Chiefs of Staff como de los Combined Boards, con el fin de demostrar que los Aliados saldrian perdiendo con una continuación de la crisis ${ }^{14}$. Ante el creciente nerviosismo de Jordana, quien no acababa de explicarse el total estancamiento de las negociaciones a pesar de haber estado haciendo él una propuesta negociadora tras otra, y dada la presión que el Consejo de Ministros en Madrid estaba ejerciendo sobre el titular de Exteriores, para Londres era un imperativo ineludible zanjar de inmediato el asunto y aceptar un compromiso con España.

Aunque Washington, ante la insistente presión diplomática, se mostró dispuesto a aceptar a regañadientes el compromiso elaborado por Hayes de permitir la exportación de 300 toneladas de wolframio para el año en curso, esto no solucionaba gran cosa el problema desde el punto de vista británico, ya que los norteamericanos seguían negándose a permitir la exportación hasta de cantidades simbólicas del mineral antes de julio de $1944{ }^{15}$, condición indispensable de toda propuesta española.

En términos generales, la discusión se centraba ahora en torno a una cantidad de 60 toneladas de wolframio; menos razón que nunca para exponerse a una ruptura con Madrid. Pero para Washington, el fondo de la cuestión no eran esas 60 toneladas; se trataba sin embargo de una posición de principio ante los neutrales.

Una seria crisis entre Londres y Washington pareció inevitable al proponer Cordell Hull que los británicos llegaran a un acuerdo por separado

14 Minuta de Roberts, 2. 4. 1944, FO 371/39648.

15 Washington especulaba que negociando ahora un acuerdo parcial para la primera mitad de 1944, posteriores negociaciones para el segundo semestre se verían solapadas por el desembarco en Francia, lo que haria esperar la posibilidad de lograr el deseado embargo definitivo. 
con España. Aunque tal propuesta causó gran extrañeza en un primer momento, Churchill no dudó en aceptarla, estando dispuesto a seguir desde entonces un camino independiente en las negociaciones sobre el wolframio.

En los últimos días de abril de 1944, los acontecimientos finalmente se sucedieron vertiginosamente. En Londres se hicieron todos los preparativos necesarios, declaración de prensa incluida, para llegar a un acuerdo por separado aceptando la última propuesta de Madrid; Roosevelt, no obstante, hizo un nuevo llamamiento a Londres mostrando su convicción de poder mejorar aún el resultado de un posible acuerdo; Hoare advertía por su parte de la inminente caída de Jordana y de las consecuencias para la posición inglesa en España, caso de no aceptarse inmediatamente un compromiso; además, en Madrid iba a tener lugar un Consejo de Ministros en el que se decidiría la exportación de una determinada cantidad de wolframio a Alemania, lo que implicaría una nueva escalada del conflicto.

Pero a fin de evitar estragos en las relaciones con Washington, Churchill decidió echarse atrás; el 25 de abril dirigía las siguientes palabras al Presidente norteamericano: "permíteme que abandone este asunto; he hecho todo lo que estaba a mi alcance, y, de ahora en adelante, te dejamos tanto la definición del rumbo a seguir como la responsabilidad de los resultados. Claro está que haremos todo lo posible por ayudaros a continuar una política que, sin embargo, no entendemos; no la criticaremos a no ser que se nos ataque a nosotros mismos" ${ }^{16}$. Estas líneas, poco presentes en la evaluación de la posición exterior del régimen, demuestran que Londres estuvo a punto de permitir un viraje sustancial en la política respecto de España.

Este telegrama, sin embargo, no fue enviado a la Casa Blanca; los norteamericanos, por su parte, habían decidido plegarse a los deseos británicos ante la insistencia de sus peticiones. Entre el 1 y el 3 de mayo tuvo, pues, finalmente lugar un intercambio de cartas entre los Embajadores anglo-americanos y el titular de Exteriores español en el que se codificó el resultado alcanzado ${ }^{17}$.

6 Proyecto de telegrama de Churchill a Roosevelt, 25. 4. 1944, FO 371/39653.

17 El Gobierno de Madrid se comprometeria: 10, a reducir la exportación de wolframio según el siguiente programa: $20 t$ en mayo, $20 t$ en junio y $40 t$ en cada mes restante del año; $2^{\circ}$, a tomar medidas efectivas para impedir el contrabando de wolframio. Caso de demostrarse una exportación clandestina de este mineral, serian reducidas respectivamente las cuotas oficiales; $3^{\circ}$, a clausurar el consulado general del Reich en Tánger y a expulsar de España a todos sus empleados; $4^{\circ}$, a expulsar a todos los agentes alemanes de espionaje y sabotaje; $5^{\circ}$, a resolver por medio de un arbitraje el contencioso acerca de los barcos de guerra italianos internados en las Islas Baleares; $6^{\circ}$, a liberar a todos los barcos mercantes italianos internados en España a excepción de 
Londres y Washington no se habían podido poner de acuerdo en utilizar el palo o la zanahoria en su política con España. Un funcionario del Foreign Office resumia estas diferencias en los siguientes términos: "Los norteamericanos tienen un concepto diametralmente opuesto al nuestro acerca de lo que es una política realista. Para nosotros quiere decir avanzar hasta aquel punto que en nuestra opinión es el más sensato. A los norteamericanos, sin embargo, lo único que les interesa es ver si pueden jugar una buena baza y en tal caso que ésta sea lo mejor posible, con independencia de las consecuencias" 18.

A partir de junio de 1944 España ocuparía un lugar cada vez menos importante en los planes estratégicos de los Aliados. Pero con eso no disminuirían los puntos de fricción entre Washington y Londres respecto de la política con España. Ahora la rivalidad se centraria especialmente en las futuras relaciones económicas una vez terminado el conflicto.

\section{INQUEBRANTABLE AMISTAD CON BERLINN E INTENTOS DE CORTEJO EN LONDRES: LA NEUTRALIDAD ESPAÑOLA EN EL ARCO DE FUERZAS DE LAS POTENCIAS BELIGERANTES}

La orientación de la política exterior española se definía en primer lugar línea por los acontecimientos en los campos de batalla. $Y$ si bien Franco había estado dispuesto a entrar en la guerra al lado del Eje ante el al parecer inminente final de la guerra después de la caída de Francia, las voces intervencionistas se fueron silenciando lentamente. La entrada de los Estados Unidos en la guerra reducia las perspectivas de una victoria alemana; y aunque en EI Pardo no se diera a Alemania por vencida, el desembarco aliado en el norte de Africa y la batalla de Stalingrado evidenciaban que ni la duración ni el resultado final podían ser augurados con seguridad.

Con el desembarco en Africa, España sería por segunda vez el punto de atención de los estrategas de ambos bandos. Para los Aliados, la neutralidad española era esencial para garantizar el éxito de las operaciones ${ }^{19}$.

dos, cuyo futuro a su vez seria decidido por medio de un arbitraje; $7^{\circ}$, a retirar de Rusia los últimos efectivos de la División Azul; $8^{\circ}$, a expulsar de Tánger al agregado militar japonés; $9^{\circ}$, a garantizar un comercio exterior sin fricciones con los paises anglo-americanos. Washington y Londres, por su parte, se comprometían a reanudar los envíos de gasolina y a preparar conversaciones sobre concesiones económicas a España.

18 Minuta de Masar, 23. 5. 1944, FO 371/39654.

19 Dwight D. Eisenhower: Crusade in Europe, London (Heinemann) 1948, pp. 102 ss. 
Por eso, tanto Hoare como su colega norteamericano cursaron al Gobierno de Madrid mensajes tranquilizadores, en que tanto Washington como Londres garantizaban la integridad del territorio español, sus colonias y protectorado ${ }^{20}$. En Africa, los alemanes fueron cogidos por sorpresa, y al encontrarse las tropas aliadas de repente en Argelia, el cierre del Estrecho de Gibraltar hubiera causado, con o sin la colaboración activa de España, más problemas que ventajas ${ }^{21}$. Con esto se habia creado una situación en que ambos bandos beligerantes estarían interesados ante todo en la neutralidad española, y con ello en la función de España como estado intermedio entre ambos bloques militares.

De esta forma, la situación exterior de España era relativamente estable; y Franco, ante el incierto desenlace de la guerra, intentaría consolidar su posición frente a ambos bandos beligerantes y mantenerse al margen de la contienda. La palabra "neutralidad" se convertiría en el vocablo más frecuentemente usado en el discurso sobre política exterior. Los bandos beligerantes, por el contrario, y en especial los países anglo-americanos, aparentemente rivalizaban por el buen entendimiento con España.

La política española respecto de Alemania se concentraria ahora en hacer votos de solidaridad con la lucha alemana, y, en particular, en invectivas contra la Unión Soviética, pero constatando que España, manteniéndose al margen del conflicto, podia jugar un papel mucho más importante a favor de Alemania que no como un aliado que, en realidad, causaría más problemas que resultados positivos. De cara a los Aliados, Jordana presentaría una política exterior basada en la auténtica neutralidad e interesada en contener gradualmente la influencia alemana en España ${ }^{22}$.

De esta forma, la diplomacia española comenzó a jugar un juego doble: por un lado, el régimen se dejaba cortejar por los Aliados, mientras que por el otro cuidaba de no enturbiar la amistad con Alemania. Según las vicisitudes de la guerra, Franco podia de este modo inclinarse más a un

20 Cfr. Hayes, misión de guerra, pp. 115-122; Hoare, special mission, pp. 172-183; Doussinague, razón, pp. 87-97.

21 Ya en enero de 1942, el Embajador alemán en Madrid había desaconsejado operaciones militares en España. Cfr. informe de Stohrer al Auswärtiges Amt, 20. 1. 1942, Akten zur Auswärtigen Deutschen Politik (ADAP), serie E, vol. I, doc. 149. Cfr. además Klaus-Jörg Ruhl: Spanien im Zweiten Weltkrieg. Franco, die Falange und das "Dritte Reich", Hamburgo (Hoffmann und Campe) 1975, pp. $125 \mathrm{~s}$.

${ }^{22}$ Respecto de los cambios políticos a raíz de la crisis de Gobierno de agosto de 1942 véase Xavier Tusell; Genoveva Garcia Queipo de Llano: Franco y Mussolini. La política española durante la Segunda Guerra Mundial, Barcelona (Planeta) 1985, p. 171. 
lado o al otro. La prosecución de esta línea política prometía estar al final de la guerra al lado del vencedor.

Al vislumbrarse cada vez más claramente que no habría una victoria completa de Alemania y de sus aliados, Franco comenzó a coleccionar "puntos" que alegar en su favor al final de la contienda, y así intentó dar a su política exterior un perfil propio que borrara la impresión de una comunidad de destino con los países del Eje.

Así, por ejemplo, la diplomacia española puso en circulación a partir del otoño de 1942 una iniciativa para inducir negociaciones de paz entre los beligerantes (el resultado ideal de la guerra desde la perspectiva española era, sin duda alguna, una paz negociada) ${ }^{23}$. $Y$ aunque estas prestaciones se vieran frustradas, y ninguno de ambos bandos beligerantes estuviera dispuesto a hablar de paz, el propósito primordial de estos llamamientos sería marcar hitos de una política exterior independiente que se pudiera hacer valer en el momento de concertarse la paz.

En este contexto, Franco vino a crear la teoría de las tres guerras que estaban sucediendo simultáneamente: la guerra de los paises anglo-americanos contra Alemania, respecto de la cual España era neutral; la guerra de Alemania contra la Unión Soviética, en la que si participaba España al lado del Eje; finalmente, la guerra del Pacífico, en la que España simpatizaba con los países anglo-americanos, por representar éstos los valores cristianos frente al paganismo.

Y para demostrar su independencia de la ideología nazi, la diplomacia española no ya solamente no continuaría haciendo votos de congruencia ideológica, sino que comenzaría a subrayar las diferencias con el nacionalsocialismo. Una de éstas podía estar representada en la política religiosa del Reich: "para que nadie pueda dudar», razonaría Doussinague, "de que actuamos con independencia del Eje y realizando una política propia,

23 Para Franco, una continuación de la contienda únicamente ayudaria al comunismo y sus proyectos de realizar la revolución mundial; una continuación de la guerra llevaría únicamente consigo poner en peligro la supervivencia de las culturas y naciones de Occidente. La gran esperanza del régimen era una paz negociada. Una y otra vez intentaría la diplomacia española, tanto en Londres como en Berlín, actuar en este sentido, infructuosamente. Incluso a finales de 1944, el Embajador en Alemania aún soñaba con el papel que Franco podría jugar en este aspecto, si los frentes de guerra pudieran estabilizarse. Esta ofensiva por la paz puede verse descrita extensamente en Doussinague, razón, pp. 150 ss. 
absolutamente nuestra, no dictada, ni siquiera sugerida, existe un medio infalible. Puesto que el Eje representa una mentalidad contraria al Cristianismo, España debe presentarse ante el mundo defendiendo la verdad cristiana" ${ }^{24}$. La defensa de la Iglesia seria, pues, a partir de ahora, una de las máximas de la política exterior, de cara al cada vez más previsible final de la guerra. Así, al promover Jordana una protesta contra la política religiosa de Berlín, no importaba el resultado positivo de la misma, cuyas posibilidades eran más bien nulas: «lo que se busca» escribiría Jordana a Vidal, «no es tanto el éxito de la gestión como el colocar a España en la postura que más conviene a sus intereses, y esto no sólo en el orden religioso, sino principalmente en cuanto a los agravios que podamos nosotros en su día alegar» ${ }^{25}$. El rumbo político que la diplomacia española estaba dispuesta a seguir hasta el final de la guerra era mantener la neutralidad, o, mejor dicho, un máximo de independencia respecto de ambos bandos beligerantes.

En Alemania se registró claramente este giro neutralista -con la consiguiente reacción negativa. Goebbels, por ejemplo, escribiría en septiembre de 1943 en su diario: «El gobierno español está intentando revisar su política exterior. (...). Y la tesis defendida ahora por Madrid es incluso curiosa: parecen creer de verdad que, en el momento en que Alemania no pueda ejercer la función de baluarte contra el bolchevismo en Europa, esta función se la pasarian los ingleses precisamente a los españoles. Partiendo de esta presunción, Franco parece sentirse bastante seguro en su posición en Europa» ${ }^{26}$.

A pesar de toda la amistad que se siguiera sintiendo en España por el Eje, el instinto de supervivencia aconsejaba tomar ciertas medidas que se dirigian en contra de la presencia alemana en España, aunque precisamente esto sería un asunto sumamente delicado. En el afán de no enemistarse con los alemanes (y tampoco de enfrentarse con los sectores intransigentes y germanófilos del régimen), Franco, en el momento de ceder a las presiones aliadas respecto de determinados aspectos concretos, optaría siempre por un "camino intermedio".

Esto se refleja, por ejemplo, en la política que se siguió en Madrid respecto de la retirada de la División Azul. "Para endulzar golpe tan duro", como justificaría el titular de Exteriores, y en contra de las recomendacio-

24 Doussinague, razón, pp. $157 \mathrm{~s}$.

25 Carta de Jordana a Vidal, 26. 7. 1943, AMAE, R-1.371/3.

26 Apunte fechado el 9 de septiembre de 1943, en: Joseph Goebbels: Tagebücher aus den Jahren 1942-43, ed. por Louis P. Lochner, Zürich 1948. 
nes originales de Vidal, Embajador en Berlín, y del propio Jordana, se optaría finalmente por la retirada parcial de la unidad, dejando en el frente la denominada "Legión Azul». Y el régimen, cada vez más seguro de su posición internacional de cara al futuro, no dudaría en utilizar un argumento que seguramente extrañaría a un Gobierno que únicamente hablaba de su victoria final: "la importancia para Alemania de una España fuerte para poder contar en el día de la paz con una voz amiga en el seno de la Conferencia de la Paz" ${ }^{27}$.

Las concesiones que estaba haciendo España respecto de las exigencias aliadas no significaban que el régimen quisiera verse en la órbita de Washington y Londres. Ante las insistentes presiones de los aliados para hacer concesiones e incluso para adoptar una posición claramente pro-aliada, Jordana replicaría con el mismo argumento de la importancia de una España independiente y fuerte: "no conviene de ningún modo al Gobierno de la Gran Bretaña desprestigiar el régimen de España". Por el contrario, cree que ha de tener interés en que España salga de esta contienda en condiciones de poder cooperar eficazmente con los vencedores, "que deben ayudarnos a ser un país fuerte y organizado, que cumpla sus fines históricos en Europa” ${ }^{28}$. Sin duda alguna, una visión un tanto ingenua.

La resistencia a cumplir plenamente tales exigencias no se basaría únicamente en los sentimientos de amistad hacia Alemania. En el momento de plantearse el embargo del wolframio, también pesaría considerablemente el argumento de las posibles represalias por parte de Alemania, si este país se veía repentinamente privado de una materia prima de tan gran valor estratégico y a cuya importación tenía teóricamente derecho debido a un acuerdo comercial firmado pocos meses antes. Aunque no se esperaba precisamente una invasión por tropas de la Wehrmacht, sí se temían en el Palacio de Santa Cruz consecuencias a nivel económico. $Y$ en el momento de anunciar al Gobierno de Berlín que dichas exportaciones tendrian que ser restringidas, Jordana no se cansaria de hacer votos de amistad con Alemania y de recordar las estrechas relaciones de los últimos años, y de las que era consecuencia la situación actual. A Jordana se le quitaría un gran peso de encima al constatar que la reacción alemana no conllevaría represalias considerables.

27 Minuta sobre la "Retirada de la División Española de Voluntarios", 25. 8. 1943, AMAE, R$1.371 / 3$.

${ }_{28}$ Protocolo de una conversación entre Jordana y Hoare, 4. 11. 1943, AMAE, R-4.294/16. 
Otro argumento que explica la intransigencia española ante determinadas exigencias aliadas son (aparte de intereses particulares como, por ejemplo, los que resultaban del negocio del wolframio) las reticencias a asumir las imposiciones de un país extranjero, una actitud generalizada en los altos mandos militares. Así, por ejemplo, Asensio, Ministro del Ejército, se opuso tenazmente a la retirada de la División Azul, e incluso Jordana, ante el comienzo de la crisis del wolframio, propuso considerar como medida a tomar la movilización general. Las consideraciones de Jordana en una carta a Orgaz son en este sentido muy caracteristicas del común sentir de los generales españoles, incluyendo al mismo titular de Exteriores: "Los aliados, cuando los asuntos en negociación con ellos estaban en madurez de estudio, han cometido la torpeza de amenazarnos con una sanción de suspensión de envío de gasolina durante el mes de febrero, creyendo que con ello iban a intimidarnos para lograr la inmediata y favorable solución de todos ellos. Aún si fuera esta su única pretensión hubiera cabido acceder hasta donde lo permitiera nuestra posición de neutral, pero $\mathrm{Vd}$. los conoce como yo y es difícil saber a dónde van con estos tanteos, y de no reaccionar ante ellos, como afortunadamente ha reaccionado el Gobierno, y con él toda España, seguramente irían en aumento sus coacciones y con ellas a tono sus desmedidas exigencias - que pudieran llegar al intento de que nuestra política neutral no lo fuera de hecho por ser demasiado parcial a su favor-o a que rompiéramos con el Eje, o a un ataque a nuestro Régimen, que al suponer un atentado contra nuestra soberania, tampoco podría tolerarse" ${ }^{29}$. El Gobierno español, no obstante la creciente presión aliada, quería mantener a toda costa una cierta capacidad de maniobra. Para fortalecer esta posición neutral, Jordana estaba dispuesto a sacrificar ciertas concesiones que se habian hecho a Alemania en los años precedentes. Esto se refería tanto a la retirada de los restos de la División Azul, como al cese del espionaje alemán en España, o al cierre del consulado alemán en Tánger.

El régimen se sentía sin embargo altamente vulnerable. Dentro de la lógica de un régimen dirigido en gran medida por militares, cabía aún que se buscase armamento para remediar la sensación de indefensión (en esto coincidirian generales de talante tan distinto como Jordana, Orgaz, Asensio, Vigón e incluso Kindelán); la lógica de los generales dio, sin embargo, también lugar a otras curiosas e ingenuas conclusiones como, por ejemplo, la de pedir a los alemanes la instalación de una fábrica de

29 Carta de Jordana a Orgaz, 7. 2. 1944, AMAE, R-1.371/1. 
carburante sintético en el plazo de seis meses para independizarse de los envios de petróleo desde ultramar: «si fuera posible hacer público que, pasado ese período, España contará con bencina sintética de fabricación propia, nuestra posición diplomática quedaría automáticamente libre de la coacción a que se nos quiere someter en la actualidad» 30 .

Aun con todo, el resultado de la crisis del wolframio fue considerado por la diplomacia española como un gran éxito. De hecho, al desistir los Estados Unidos de su ultimátum para un cese definitivo de los envios de wolframio a Alemania, logrado en parte por la inflexible posición española, se abrieron las puertas a una solución negociada, en la que se salvó finalmente la conditio sine qua non de la posición española: la posibilidad de recomenzar el envio de wolframio a Alemania (aunque fueran cantidades simbólicas) y evitar por lo tanto la apariencia del embargo real, salvando de esta forma la impresión de haber obrado por imposición de los Aliados. Además, la diplomacia española logró demostrar su buena disposición hacia Alemania y su ahínco por lograr el mejor resultado posible para el Reich y evitar por tanto mayores estragos en las relaciones bilaterales. Tras solucionarse satisfactoriamente (en un sentido u otro para todos los implicados) la crisis, el Palacio de Santa Cruz había logrado de cara al futuro la posibilidad de mantener relaciones lo más cordiales posibles con ambos bandos beligerantes.

Después del acuerdo de mayo de 1944 parecian haberse solucionado todos los problemas pendientes entre los Aliados y España. Pero una cosa es llegar a un acuerdo y otra es cumplir lo acordado. Mientras que lo estipulado respecto de la retirada de la Legión Azul o de los barcos italianos fue cumplido por parte española sin mayores demoras, tanto el espionaje alemán como el contrabando de wolframio serían motivo de continuos roces entre la diplomacia española y la aliada. En el caso del wolframio, los precios exhorbitantes que se pagaban por dicho material hacian prever intentos de corrupción de la administración (el mismo subsecretario de Asuntos Exteriores confesó que un solo camión de wolframio, sin lugar a dudas, bastaría para comprar íntegramente la aduana española) y de exportación ilícita de este mineral; y no pasaria mucho tiempo hasta que la Embajada británica denunciase los primeros casos de contrabando de wolframio. 
Pero aunque Jordana advirtiera una y otra vez de las complicaciones que esta situación conllevaría a nivel internacional, fue realmente poco lo que pudo hacer en esta materia, que no era de su competencia directa. Bastante significativa es la carta que envió a comienzos de mayo de 1944 a Carrero: "creo fundamental que esto se lleve con el máximo rigor si no queremos echar por tierra todo lo logrado después de esta penosísima negociación, que a mi, por mi parte, me sería poco menos que imposible emprender otra análoga provocada por trapacerias innecesarias y a las que tan dados somos. Por mi parte he escrito al Ministro de Hacienda y al Jefe del Alto Estado Mayor (...); pero de nada valen (estas cartas) si no tienen el apoyo del Generalísimo. Creo que es mucho lo que se juega España para no poner todo el empeño en evitarlo" ${ }^{31}$. Los intentos de Jordana de controlar el contrabando fracasaron, y, a pesar de todo, atravesarian la frontera con Francia unas 500 toneladas de wolframio; únicamente la retirada de las fuerzas alemanas de la frontera del Pirineo, a mediados de agosto de 1944, haría imposible la continuación del contrabando. Estragos serios con los Aliados, no obstante, no se produjeron, ya que éstos culparían de los hechos ocurridos a la ineficacia y obstrucción por parte de la administración y no de la diplomacia española.

Una suerte parecida a la del wolframio correrían los intentos por parte del Palacio de Santa Cruz de deshacerse de los agentes de espionaje alemanes ${ }^{32}$. Si bien hasta mediados de 1943, la diplomacia española no puso demasiado interés en frenar las actividades de espionaje alemanas, esta situación cambió paulatinamente a partir de la segunda mitad del año 1943. Veamos unos extractos de unas cartas que dirigiría Jordana a Orgaz a propósito de los manejos de los alemanes en Tánger. A finales de julio escribiría: "es de gran conveniencia ver lo que haya de razón en las quejas aludidas para quitar a ingleses y norteamericanos toda ocasión de nuevas reclamaciones que el día de mañana pudieran servir de pretexto para justificar más graves actitudes" ${ }^{33}$. Un mes más tarde, al no constatarse una especial cooperación por parte del Alto Comisario, Jordana cambiaría de tono: "se acabaron aquellos tiempos en que por propia conveniencia se apelaba a ingeniosos procedimientos para ayudar abiertamente a los paises del Eje. (...). No hay que olvidar que hoy son ahí nuestros vecinos los países aliados, y que por lo tanto nos conviene

31 Informe al Subsecretario de la Presidencia del Gobierno, 4. 5. 1944, AMAE, R-4.294/17

32 Cfr. Carlos Collado Seidel: «España y los agentes alemanes, 1944-1947. Intransigencia y pragmatismo político", en: Espacio, Tiempo y Forma, Serie V, Ho Contemporánea, vol. 5 (1992), pp. $431-482$.

33 Orden de Jordana a Orgaz, 27. 7. 1943, AMAE, R-1.773/2. 
sostener con ellos las más amistosas relaciones" ${ }^{34}$. $Y$ en febrero de 1944 , las palabras del titular de Exteriores eran aún más drásticas: "ahora bien; hay una cuestión que no admite aplazamientos ni la menor lenidad, y es la de la persecución del espionaje, muy especialmente del alemán, que se ha fomentado extraordinariamente y hay que cortar de raíz. Este asunto no admite ya subterfugios ni habilidades, sino una enérgica decisión, expulsando sin contemplaciones a los alemanes que enreden en nuestra zona" ${ }^{35}$.

Pero todo propósito de expulsar de España a estos agentes de espionaje tendria su limite al chocar con los intereses de otros grupos influyentes. Así, por ejemplo, la Embajada alemana logró obtener de las autoridades españolas la concesión de no expulsar a ningún alemán directamente, quedando este cometido a cargo de la propia Embajada, y limitándose el Palacio de Santa Cruz a ordenar el traslado de residencia de aquellos agentes descubiertos y denunciados por los Aliados fuera de sus habituales campos de operación. $Y$ a pesar de clausurarse el 16 de mayo de 1944 de forma definitiva el consulado alemán de Tánger, Jordana permitiría a los alemanes continuar mandando telegramas en cifra, y les concedería un amplio margen de tiempo para finalmente abandonar el edificio.

Dada la estrecha colaboración que existía tanto entre la Gestapo y los servicios de Seguridad del Estado español como entre los mandos militares alemanes y el Alto Estado Mayor, también por este medio se obstruiría considerablemente la labor de expulsar a los agentes alemanes. Estos servicios españoles, por tanto, defenderian el trabajo de sus compañeros alemanes, o intercederian repetidamente a favor de un grupo de agentes alemanes que, por ejemplo, suministraba informaciones sobre los movimientos de los "maquis" en el sur de Francia. El Jefe del servicio militar de espionaje alemán, Canaris, realizaría frecuentemente viajes a España, e incluso en octubre de 1943, al intensificarse los intentos de la diplomacia española de restringir el trabajo de estos servicios, obtendría el permiso de mantener de momento las redes establecidas ${ }^{36}$.

De esta forma, aun con todas las medidas tomadas desde el Palacio de Santa Cruz (Jordana, por ejemplo, expondría al Consejo de Ministros un proyecto de ley que preveía el delito de "quebranto de neutralidad", sometiendo a sus infractores a sanciones severas, análogas a las de rebelión en el fuero militar), las redes de espionaje alemanas continuarían

34 Carta (proyecto) de Jordana a Orgaz, 1.9.1943, AMAE, R-1.773/2.

Carta de Jordana a Orgaz, 7. 2. 1944, AMAE, R-1.371/1.

Heinz Höhne: Canaris, Patriot im Zwielicht, München 1976, pp. 509 s. 
trabajando sin mayores complicaciones. Muy caracteristicas en este sentido son las siguientes expresiones de Orgaz en defensa de los agentes alemanes en Tánger: "dichas actividades alemanas, que indudablemente se practican y seguirán practicándose en tanto viva un alemán entre nosotros, se llevan a cabo, mi General, de manera tan discreta, que por nadie se advierten. Puedo asegurarle que proceden, en lo que a nuestros respectos se refiere, con gran corrección. Yo por mi parte no encuentro ocasión para acusarles" ${ }^{37}$.

Además, un nuevo factor complicaría aún más la expulsión de estos alemanes: la protección por parte de sectores influyentes del régimen. La expulsión de determinados alemanes que desde el punto de vista del régimen merecian toda consideración, bien sea por servicios prestados, o por sus largos años de residencia en España - su número crecería vertiginosamente de un mes a otro-, no se llevaría finalmente a efecto. Hasta junio de 1944, de los 220 agentes alemanes denunciados por los Aliados, sólo 19 habían sido expulsados; hasta finales de septiembre esta cifra no pasaría de 57. En noviembre de 1944 la Embajada británica constataria que las autoridades españolas eran o contrarias o incapaces de obrar con seriedad en esta cuestión ${ }^{38}$.

El 24 de mayo de 1944, Churchill pronunciaria un discurso ante los Comunes que tendría un gran impacto en España y que confirmaría al régimen en su política exterior. El Primer Ministro británico afirmó en esta ocasión que, por lo que se refería al régimen político interior de España, éste no era problema en que Inglaterra tenía que intervenir, y que todo hacía pensar que España ejercería en el futuro un papel importante para la pacificación del Mediterráneo y para la normalización de la política después de la guerra.

Churchill estaba dispuesto a otorgar un papel primordial a España -a causa de su ubicación estratégica y dadas las reservas respecto de la futura Francia- como potencia regional en el Mediterráneo occidental. Muy significativas son en este sentido las frases poco conocidas que dirigió al Presidente norteamericano: «Franco no me importa demasiado, pero en ningún caso quiero tener una España hostil hacia la Gran Bretaña después

37 Carta de Orgaz a Jordana, 19. 2. 1944, AMAE, R-1.371/1.

38 Informe de Bowker a Eden, 7. 11. 1944, FO 371/39722. 
de la guerra. No sé en que medida voy a poder contar con la Francia de De Gaulle; Alemania va a tener que ser suprimida por la fuerza; y a nosotros se nos presenta una alianza de 20 años con Rusia. Recuerda que todo esto nos pilla aquí muy de cerca" ${ }^{39}$. Estos son precisamente los mismos argumentos que, meses más tarde, utilizaría Franco en su carta a Churchill. Claro está que esta política dependería del rumbo que siguiera el régimen; $y$ el Foreign Office, al no evolucionar el régimen en el sentido deseado, se encargaria de soslayar los proyectos del Primer Ministro.

Sin embargo, aquel discurso de Churchill tuvo un efecto sumamente tranquilizador en Franco; fue como una carta blanca para su régimen y una garantía para su integridad. Con las palabras de Churchill, Franco pudo comenzar a albergar la seguridad de salvar el futuro de su régimen, incluso con una derrota total del Eje. Las advertencias desde Berlín de que $\sin$ la victoria de las armas alemanas no existiría en el futuro ni una España Nacional ni, en general, ningún otro Estado Nacional en Europa, habian perdido su carácter amenazante.

A partir de este momento, y ante la ya virtual victoria de los Aliados, Franco, que se sentía cada vez más cortejado por Londres, ve incluso la posibilidad real de una alianza con la potencia líder de Europa, pretensión que perseguirá tenazmente hasta recibir la negativa definitiva de Londres a comienzos de 1945. Durante una conversación mantenida con Hoare en junio de 1944, Franco expondría ampliamente a éste sus proyectos para el futuro: Partiendo de los «muchos puntos de contacto y de coincidencia en lo que se refería al porvenir de Europa", y de que los puntos de fricción (wolframio, agentes de espionaje) eran en definitiva insignificantes y únicamente resultado de una campaña de los medios de comunicación, sólo cabía una estrecha colaboración política entre España y la Gran Bretaña. Ambos países, según esta argumentación, tendrían que defenderse en el futuro de la amenaza comunista; y ambos tendrían que plantar cara a los Estados Unidos, que tendían a poner a toda la América del Sur bajo su influencia, no sólo suplantando los intereses británicos allí establecidos, sino también minando el terreno a la cultura hispana y buscando su anulación. La conclusión lógica de Franco era: «Por consiguiente, hay muchos puntos de contacto entre los intereses de la Gran Bretaña y de España, y podemos mutuamente ayudarnos en estas coincidencias en beneficio de Europa, pues salvando la civilización europea se salvará la civilización del mundo" ${ }^{40}$.

39 Telegrama de Churchill a Rooseveit, most secret and personal, 4. 6. 1944, FO 371/39669.

40 Protocolo de una conversación entre Franco y Hoare, 12. 6. 1944, AMAE, R-1.372/22. 
Para Franco, la momentánea propaganda anti-franquista en la Gran Bretaña y en los Estados Unidos era únicamente el resultado del apasionamiento de los tiempos de guerra, que necesariamente tendría que apaciguarse y dar paso al "sano egoísmo" de las naciones, que se rige por factores pragmáticos de política internacional y no por conceptos morales.

A la muerte de Jordana no habría tampoco cambios en la política exterior del régimen. El nombramiento de Lequerica, hasta entonces Embajador en Vichy, para la cartera de Exteriores, sirvió, sin duda, a Franco para librarse de una legación cada vez más embarazosa; también se debió a la incondicional fidelidad de Lequerica a Franco y al régimen ${ }^{41}$. Sin embargo, cabe asímismo pensar que, con este nombramiento, Franco quiso subrayar su política de acercamiento al Gobierno de Londres. Las primeras reacciones británicas fueron al menos contradictorias. Si bien era visto como un oportunista, que había mostrado en Vichy un talante falangista y germanófilo, también -y en contra de los resultados de la investigación histórica hasta el momento- existían indicios que permitían esperar una influencia positiva (en el sentido de Londres) en la política exterior española, recordándose por ejemplo su pasado de defensor vehemente de la Monarquía ${ }^{42}$. Incluso Alba se apresuró a escribir a su amigo Templewood ${ }^{43}$, elogiando las cualidades del nuevo Ministro de Exteriores: "Nos hemos enterado por la radio de que José Félix Lequerica ha sido nombrado sucesor de Jordana. Lequerica es un viejo amigo, y estoy convencido de que su inteligencia es una garantía para el éxito de su cometido en estos tiempos tan difíciles" ${ }^{44}$. Después de esta actitud de expectativa ante el rumbo político que tomaría el nuevo titular de Exteriores, se confirmaría que, por el momento, no habria cambios en la política pro-británica del Palacio de Santa Cruz.

Pronto, sin embargo, se demostraría que no iban a existir posibilidades de compaginar las aspiraciones de la política exterior española y la anglo-americana; y cada vez se veria más claramente que los conceptos políticos de que partían ambas cancillerías eran incompatibles. Franco continuaría con su política de consolidación del régimen -por ejemplo, por medio del fortalecimiento de las milicias falangistas y con una crecida

41 Cfr. Tusell; G. Queipo de Llano, Franco y Mussolini, p. 259.

42 La primera reacción del Embajador británico había sido: "Un diplomático de carrera. ¿Por qué no?" Notas manuscritas fechadas el 11./12. de agosto de 1944, Tem., XIII: 13. Cfr. además el informe de Templewood a Eden, № 15, 11. 8. 1944, Templewood Papers (Tem.) XIII: 24.

43 A Hoare le había sido otorgado en julio de 1944 el título de Vizconde de Templewood.

44 Carta de Alba a Templewood, 11. 8. 1944, Tem., XIII: 7. 
represión política- y rechazaría toda intromisión en asuntos internos. Los británicos (y también los norteamericanos), sin embargo, esperaban reformas radicales en las estructuras del régimen que llevaran a una paulatina democratización del sistema político, y que facilitaran su aceptación en el concierto de naciones de postguerra. En su primera carta al nuevo Ministro, Alba no le dejó dudas al respecto: “el régimen actualmente imperante en España está tildado de germanofilia congénita y nunca por esto, además de otras razones de orden democrático, será bien visto. (...) Por el bien de España vuelvo a insistir en mi opinión, tantas veces expresada, de no caber otra salida que el próximo retorno de la Monarquía porque ésta vendría sin esos resabios que por fuerza, y es justo reconocerlo, hubo de tener en los comienzos de la guerra el presente régimen (...). El Gobierno británico no tiene ninguna simpatía por ese régimen, ni la tienen, no digo las izquierdas, sino casi nadie aquí, y si ahora se abstienen de todo comentario es por razones transitorias" ${ }^{45}$.

Pero estas advertencias traian sin cuidado a la diplomacia diseñada en Madrid. Franco, a quien nunca se le pasó por la cabeza dejar el poder por indicación de Londres, seguía teniendo presente el discurso de Churchill, o al menos el pensamiento político que de éste se desprendía. De la respuesta de Lequerica a Alba, respuesta seguramente consultada con Franco, se deduce la creencia de que el pragmatismo prevalecería en la política inglesa después de concluir la guerra, ya que la no-intromisión en asuntos internos de otros paises fue "doctrina general y siempre practicada por el realismo de los políticos ingleses». Era sin duda la firme convicción de Franco de que «atravesamos ahora (...) un periodo de contradicción violento en el cual todas las pasiones están encendidas y los juicios un poco oscurecidos en los países beligerantes; pero cuando llegue la paz -y pienso que ese día no está lejano- volverán la serenidad y el sano egoísmo a dirigir la política de los principales, y especialmente de Inglaterra" ${ }^{46}$. La orientación internacional de España y no su régimen interior debía constituir por tanto el tema de diálogo con Londres.

La carta que enviaría Franco por conducto de Alba al Primer Ministro británico se encuadra perfectamente en esta línea de la política exterior española. Al mismo tiempo resultaría ser el último y más apremiante intento del régimen por ganarse las simpatías de la Gran Bretaña, presentado a ambos paises en una comunidad de destino ante la amenaza

45 Carta de Alba a Lequerica, 18. 8. 1944, AMAE, R-1.373/23.

46 Carta de Lequerica a Alba, 17. 9. 1944, AMAE, R-1.373/23. 
comunista. Después de la destrucción de Alemania y ante la "subversión comunista» en Europa -incluyendo a Francia e Italia- era lógico, desde el punto de vista del régimen, buscar una alianza con la Gran Bretaña para hacer frente al bolchevismo ${ }^{47}$.

Londres, sin embargo, no reaccionaría en la forma deseada por Madrid. El mundo visto desde El Pardo no sería compatible con los proyectos de futuro diseñados en el Foreign Office. Bastante ilustrativo es, en este sentido, la reacción de Eden al leer la comunicación de Franco: «mi primera impresión es que esta carta demuestra una visión de la realidad que no tiene nada que ver con la situación del mundo actual»» ${ }^{48}$.

Desde comienzos de 1944, estaba claro para el régimen español que Alemania no ganaría la guerra. Seguía existiendo la esperanza de una paz negociada. No obstante, Franco nunca cuestionó su amistad con Alemania. A finales de enero de 1944, decía a Hoare: "España es un país digno, y, caso de ser destruida Alemania, no sería ella quien le pusiera el pie al cuello. Quédese eso para los vencedores..." $49 ; y$, refiriéndose a los agentes alemanes, constataria: "no es posible a un país con el cual se mantienen buenas relaciones y con el cual en tiempo no lejano se mantuvo a causa de nuestra guerra civil una pequeña colaboración, decir que en veinticuatro horas tienen que hacer las maletas y marcharse un número determinado de personas, algunas de las cuales llevan varios años residiendo aquí" 50. El final de la crisis del wolframio brindó a régimen español, sin duda alguna, la posibilidad de distanciarse del Reich; pero, no obstante, Jordana abogaría por un futuro en que las relaciones con Berlín fueran, a ser posible, incluso más estrechas.

En noviembre de 1944, Franco consideró necesario demostrar nuevamente su independencia del Eje y de toda ideología fascista, declarando a una agencia de prensa que España en ningún caso podía haber sido un aliado del Eje, ya que España no podría nunca aliarse con naciones cuya política no se rigiere por los principios de la doctrina católica. Vidal, que estaba entonces primordialmente ocupado en evacuar su personal de

Carta de Franco a Alba, 18. 10. 1944, FO $371 / 39672$.

Carta de Eden a Bowker, top secret, 21. 11. 1944, FO 371/39671.

Protocolo de una conversación entre Franco y Hoare, 28. 1. 1944, AMAE, R-4.294/16.

Protocolo de una conversación entre Franco y Hoare, 12. 6. 1944, AMAE, R-1.372/22. 
Berlín, se apresuraría a asegurar al Gobierno del Reich que España se mantenia firme en su amistad con Alemania. En la segunda mitad de noviembre - las tropas americanas, inglesas y rusas estaban ya luchando en territorio alemán y se avecinaba el apocalipsis del Reich--, Vidal prefirió recavar una confirmación de la política con Alemania. Pero incluso ahora, igual que meses antes con Jordana, no se consideraría la ruptura con Alemania.

\section{LA GRAN CONSPIRACIÓN. INTENTOS Y FRACASOS DE DERROCAR AL RÉGIMEN}

Finalmente no se había cumplido la esperanza de que con la destrucción del fascismo y del nacional-socialismo automáticamente se abriria un proceso de evolución del régimen español que llevaría a la desaparición de la Falange y la retirada de Franco del poder. En 1942, como lo demuestran sus informes a Londres, Hoare aún se sentía muy seguro de una evolución del régimen en el sentido indicado. En ese mismo año, el State Department e incluso el Foreign Office habían considerado una y otra vez el derrocamiento del régimen de Franco por medio de una intervención directa o indirecta (apoyando a grupos de oposición), pero finalmente siempre se aplazaría en Londres una decisión en este sentido hasta lograr una sólida situación militar en los frentes. Sin embargo, las concesiones hechas a los aliados y el acentuado viraje neutralista del año 1943 generalizaron en Londres la esperanza en una evolución (democrática) del régimen.

Pero la posibilidad de esta evolución positiva decreció considerablemente a partir de finales de 1943. E incluso las serias advertencias de los políticos aliados que visitaron Madrid por estas fechas no impresionaron en lo más mínimo a la diplomacia española. De la misma forma se verían frustrados los intentos de sectores monárquicos del régimen por lograr la restauración de la monarquía. Incluso con la conclusión del acuerdo de mayo de 1944 se esperó en Londres poder enlazar con la evolución positiva que había tenido lugar un año antes; y más aún, ahora que el peligro de una invasión alemana en España había desaparecido definitivamente. En Inglaterra se estimaba que los españoles deberían dirigir sus esfuerzos a ayudar a los aliados a obtener un rápido final de la guerra.

Franco, sin embargo, no daba señales de querer introducir cambios en su régimen; todo indicaba, por el contrario, que estaba intentando perpetuar 
su liderazgo. Con este régimen, los Aliados no veían ninguna posibilidad de mejorar las relaciones bilaterales. $Y$ aunque fuera posible acabar con la ayuda española a Alemania, el Foreign Office estaba seguro de que Franco y su Gobierno seguirían siendo hostiles hacia los Aliados y sus ideales. En Londres no se veía la posibilidad de llegar jamás a unas relaciones cordiales con Franco. La conclusión era, por tanto, lograr que Franco abandonara el poder cuanto antes.

Ante esta situación de creciente intransigencia por parte de Franco y dada su voluntad manifiesta de aferrarse al poder (aunque los diplomáticos ingleses en España afirmaran continuamente que su Gobierno no tenía intención alguna de entrometerse en asuntos internos españoles), el Foreign Office optaría por presionar con más fuerza en Madrid. El desembarco de los Aliados en Normandía ofreció la posibilidad de comenzar esta nueva ofensiva; ahora ya no existía la necesidad de tener una España estable y tranquila por razones estratégicas. El Foreign Office no abogaría por la utilización del arma del petróleo como había sido la intención de los norteamericanos, sino que presionaria a nivel diplomático para inducir una evolución "voluntaria» del régimen. A comienzos de junio de 1944, Hoare, en conversación con Jordana, haría su primer ataque directo contra la Falange, indicando que incluso en círculos conservadores ingleses se aborrecía la Falange y que la opinión pública no veia, por lo general, diferencia alguna entre el Falangismo y el Fascismo. Hoare indicaría por estas semanas con gran insistencia que España tenia ante sí la mejor oportunidad en muchos años para afianzar su posición internacional, pero que tendría que aprovecharla rápidamente, ya que tal oportunidad no habria de prolongarse por mucho tiempo. La victoria aliada no se haría esperar mucho, y España debería actuar antes de que ésta se produjera.

Pero Hoare, que sin duda hubiera querido coronar su misión en España como artífice de la democratización del país, no sólo perseguiria este propósito a nivel diplomático, sino que lo intentaría también fomentando la oposición monárquica contra el régimen. El punto álgido de esta política personal -nada indica que las esferas gubernamentales estuvieran enteradas de estos manejos conspirativos y menos que los aprobaran- se dio en una cena privada en casa de los Condes de la Maza el día 30 de junio de 1944, a la que también asistió el propio Jordana. Aunque sólo podemos reconstruir parcialmente el transcurso de la vela$\mathrm{da}$, parece claro que Hoare, acompañado de su agregado militar, aprovechó la ocasión para lanzar un ataque frontal contra el régimen y forzar una decisión por parte del sector monárquico del régimen; atacó duramente a la Falange y recomendó abiertamente la Monarquía como la 
forma de gobierno ideal para España. Finalmente advirtió del peligro que resultaría de no considerarse sus palabras. Hoare, que veía en Jordana a un aliado suyo en la lucha contra la Falange, seguramente no se percató de la posible reacción del ministro español, quien a la mañana siguiente, lo primero que hizo fue redactar un detallado informe para Franco. Al margen de sus personales opciones políticas, Jordana era ante todo un fiel funcionario al servicio del Estado. El Jefe del Estado dio instrucciones ese mismo día a Jordana para poner coto a la incitación a la conspiración por parte del Embajador británico ${ }^{51}$. El titular de Exteriores citó a Hoare en el Palacio de Santa Cruz y le expuso claramente lo que pensaba: "me permito señalar al Embajador en ese mismo tono amistoso, que no se mezcle en esta clase de cuestiones ni dé amparo en la Embajada a los que tratan de apoyarse en ella para sus manejos. Esto no favorece a nadie y menos a la Embajada y a su país; y en cuanto a la instauración de la Monarquía, nada puede perjudicar más que el que aboge por ella un país extranjero" ${ }^{52}$.

El consiguiente estado de desilusión parece haber sido la causa de la reacción del Embajador británico, al abandonar repentinamente, con todo su séquito y sin despedirse del Jefe del Estado, una recepción que tuvo lugar en el Palacio de La Granja el 18 de julio de 1944 por el hecho de que la esposa del Ministro del Ejército sentara a la señora del Embajador alemán junto al mismo Embajador británico. El Foreign Office no sólo consideró exagerada la reacción de Hoare sino que también se negó a hacer del suceso una crisis de mayor trascendencia.

España había perdido toda su anterior importancia estratégica, y el Embajador británico, después de fracasar en sus intentos conspirativos, de ahora en adelante no dejaría pasar oportunidad sin indicar que eran necesarios cambios políticos en el régimen. $Y$ dado que las quejas de Templewood no cesaban, el Gobierno español, hasta entonces aparentemente dispuesto a cooperar con Londres, comenzó a reaccionar con terquedad. Así, por ejemplo, al protestar Templewood contra las ejecuciones por delitos cometidos durante la guerra civil, Lequerica replicó argumentando que Franco mismo le habia asegurado que las ejecuciones de índole política habian cesado, y ahora ya únicamente se procedía contra criminales comunes; o, al manifestar el Embajador que no albergaba esperanzas en el porvenir del país mientras no tuviera lugar una

51 Las correspondientes cartas, fechadas el 1 de julio de 1944 de Jordana a Franco y la respuesta de éste al primero están reproducidas parcialmente en Suárez, Franco, III, pp. 507 s.

52 Nota al Embajador de Inglaterra, sin techa (primeros de julio de 1944), AMAE, R-1.372/22. 
reconciliación de los españoles, el Ministro contestaría que los españoles de por sí eran irreconciliables. Toda clase de crítica contra el régimen era ahora rechazada. A mediados de septiembre el Foreign Office constataría este cambio de actitud. Una impresión que se confirmaría en las semanas siguientes.

En Londres no se veía remedio contra esta evolución inesperada. Mientras que en julio Hoare estaba aún convencido de que el régimen de Franco sería derrocado al final de la guerra mediante un golpe de estado, ahora se confirmaria definitivamente que, aun con la derrota del Eje, no sólo no habría cambios en el régimen español sino que incluso se fortalecería la propia posición de Franco y la de la Falange. Londres vería a partir de ahora claramente que la derrota de Alemania no provocaria automáticamente una conversión de Franco.

No obstante, se seguiría descartando la utilización de sanciones económicas contra el régimen. En septiembre de 1944 ya se cristalizaban los planes económicos para la postguerra; Londres no quería desechar las posibilidades que ofrecía el mercado español para la economía británica, y la utilización del arma económica incluso hubiera perjudicado en cierta medida a la propia economía. La excelente posición alcanzada respecto del comercio con España no debía ser puesta en peligro, con Franco o sin Franco.

También el Embajador norteamericano lanzó una ofensiva para lograr que Franco introdujera cambios en su política exterior e interior. En la segunda mitad de 1943 escribió a Jordana para incitar al Gobierno español a no ser tan intransigente con la Unión Soviética, ya que ésta sería un poder fáctico después de la guerra que había que tener en cuenta. Posteriormente también arremeteria contra la Falange, indicando que precisamente el partido resultaba ser un gran obstáculo para el restablecimiento de relaciones cordiales entre ambos paises. Pero, en contraste con las cada vez más ásperas relaciones entre Hoare y Lequerica, las entrevistas entre éste y Hayes estaban marcadas por una cordialidad acentuada. Esto no seria visto con agrado por el Foreign Office, que incluso constataría que Hayes se estaba convirtiendo en uno de los más firmes apoyos de Franco. $Y$, si el Embajador británico exigía cambios sustanciales en el régimen, el norteamericano insinuaría que determinadas reformas (cosméticas) -por ejemplo en la apariencia del partido- y la demostración de una buena disposición con respecto a los Estados Unidos tendrian un efecto saludable en las relaciones bilaterales.

De hecho, en estos últimos meses del año 1944, la política norteamericana hacia España fue mucho más moderada que en la primera 
mitad del año. Esto se debió en buena medida al gran interés que tenían los norteamericanos en llevar a buen término las negociaciones sobre el uso de aeropuertos españoles por lineas comerciales norteamericanas que habian sido retomadas después de una larga interrupción. Estas fueron concluidas en diciembre de 1944 e incluso ampliadas con un protocolo adicional que permitiría al Air Transport Command norteamericano realizar escalas en España; una concesión importante, pues significaba dar facilidades militares a un país en guerra por parte de otro país oficialmente neutral ${ }^{53}$. Poco tiempo después, con el nombramiento de un nuevo Embajador norteamericano en Madrid, cambió radicalmente el panorama: el 10 de marzo de 1945 escribía Roosevelt a su nuevo Embajador una carta en la que afirmaba que con Franco y la Falange nunca podrian establecerse relaciones cordiales.

A primeros de octubre de 1944 viajaria Templewood a Londres. El cercano final de la contienda y la posición intransigente de Franco exigian un replanteamiento de la política con España. Templewood, considerando terminada su misión en la Península Ibérica, redactó un amplio informe en el que constataba que la política de intentar propiciar un cambio político en España había fracasado. Por el contrario, Franco parecía estar convencido de poder continuar manteniendo su política dictatorial en el interior $y$ al mismo tiempo relaciones cordiales con los Aliados ${ }^{54}$.

Ante el temor de que la opinión pública inglesa forzara una política restrictiva hacia España que imposibilitaría el mantenimiento de relaciones normales -necesarias para garantizar tanto la seguridad en el Estrecho de Gibraltar como el desenvolvimiento del comercio bilateral- Templewood recomendó la continuación y un posible aumento de la presión diplomática y económica contra el régimen de Franco, con el fin de lograr finalmente quizás por este medio el anhelado cambio de régimen. Estas propuestas, sin embargo, no fueron bien acogidas en el Foreign Office. Cadogan argumentaría que la situación económica mundial presentaba un estado tan deplorable que no permitía el lujo de decretar sanciones económicas por razones ideológicas. Con esto, claro está, no se daba a entender que hubieran de existir relaciones cordiales con Franco a nivel político. La única propuesta del memorándum de Templewood que el Foreign Office estaria dispuesto a considerar era advertir una vez más a Franco que su régimen

53 Hayes, misión de guerra, pp. 334 s. y 343 ss.; Antonio Marquina Barrio: España en la politica de seguridad occidental, 1939-1986, Madrid (Servicio de Publicaciones del EME) 1986, pp. 112 ss.

54 Memorándum de Templewood, 16. 10. 1944, FO 371/39.671. 
no estaba cualificado para integrarse en la comunidad internacional de postguerra.

En medio de estos planteamientos llegaria la carta de Franco a Churchill, brindándose con ello al Foreign Office la oportunidad para hacer a Franco la mencionada advertencia. La respuesta que el Primer Ministro británico daría finalmente, aunque con reticencias (Churchill seguiría oponiéndose a entrometerse en los asuntos internos de España) a Franco, no dio, como era de esperar, fruto alguno.

Al fin y al cabo, la "no reconversión» de Franco tendría un resultado "positivo", ya que, según diría un funcionario del Foreign Office, "la situación más embarazosa de todas hubiera sido un general Franco disolviendo la Falange y pidiendo su aceptación como converso a los ideales de las Naciones Unidas» 55.

Templewood abandonó España a mediados de diciembre de 1944. EI Eje había sido derrotado pero las esperanzas de un cambio de régimen en España no se habian cumplido. Templewood confesaba a su homólogo norteamericano: "Jamás conocí a tantas gentes haciendo acto de fe monárquica (...) y, en realidad, no deseando a un Rey" ${ }^{56}$.

\section{LA POLITICA EXTERIOR ESPAÑOLA, ¿UN ÉXITO?}

La política exterior española de los años 1942 a 1945 estuvo guiada en primer lugar por el deseo de mantener un margen de maniobra lo más amplio posible, a fin de poder "navegar" con suficiente holgura a través del agitado mar de ambos bandos beligerantes. Franco intentaria mantener al mismo tiempo relaciones amistosas tanto con los paises angloamericanos como con el Eje.

La política exterior de Franco mostró al mismo tiempo una capacidad de adaptación a las circunstancias del momento y una flexibilidad asombrosas. Su política abiertamente germanófila de los primeros años de guerra y su ayuda material a la causa del Eje (enviando la División Azul al frente de Rusia o tolerando las actividades de espionaje alemanas en España) fue paulatinamente dando paso a concesiones a los Aliados. De esta forma, cortando casi todo el suministro de wolframio a Alemania, incluso quebró un acuerdo comercial con este país, a la vez

55 Minuta de Roberts, 24. 9. 1944, FO 371/39.677.

56 Hayes, misión de guerra, p. 342. 
que permitió a las fuerzas aéreas norteamericanas hacer escala en España.

Esta política de "navegar" entre los bloques y mantener con ambos unas relaciones lo más cordiales posibles culminó aparentemente en el discurso de Churchill el 24 de mayo de 1944. La política británica se mostraba satisfecha con el rumbo exterior español, y se comprometía a respetar el régimen interno; al mismo tiempo habia logrado que los alemanes aceptasen duros reveses en su presencia en España, pero sin resultar de ello un grave detrimento para la cordialidad de las relaciones bilaterales.

Después de resolverse la crisis del wolframio, Washington acusaría a Londres de haber abandonado prematuramente una actitud firme respecto del régimen de Franco. En aquellos meses, el Departamento de Estado no habia tenido reparos en complicar al régimen aún más la situación, incluso a sabiendas de que ello podría originar un caos y hasta una sublevación en España. Si los Aliados se hubieran aferrado a la exigencia de un embargo total del wolframio, no es improbable que se hubiera llegado a una situación sumamente embarazosa para el régimen. Londres, sin embargo, se opuso tenazmente a seguir exigiendo del Gobierno de Madrid el cumplimiento de todas las exigencias presentadas, y obligó a Washington a desistir de sus planes. Para el Foreign Office, en política internacional no se resolvía nada con aplastar al adversario político. No obstante, la crisis del wolframio de 1944 sería la última situación en que al menos una parte del bloque anglo-americano se planteara en serio provocar la caída de Franco, y estuviera, además, a punto de causar un cambio de actitud en la otra parte.

Londres, sin embargo, nunca creyó en la política del "palo». El Foreign Office estaba seguro de que su propia táctica de la "zanahoria» sería mucho más efectiva en el momento de tratar con España. Partiendo del supuesto de que el régimen evolucionaría necesariamente en el sentido deseado, una vez que la suerte de la guerra estuviera con los Aliados, y sin enemistarse hasta entonces con España, sólo cabía pensar que Madrid secundaria de una forma $u$ otra los deseos de los Aliados. Londres consideraría que el establecimiento del segundo frente originaría un cambio de actitud en el régimen de España. Estos pronósticos, sin embargo, no se correspondieron a fin de cuentas con la realidad. 
A partir de junio de 1944 comenzaría a oscurecerse el horizonte de la diplomacia española. La discrepancia fundamental entre los Aliados y el régimen se manifestaría abiertamente en el momento en que para los Aliados no sería ya necesario asegurarse de la neutralidad española por razones estratégicas. A partir de entonces se haría cada vez más evidente que la concepción política y las metas de futuro de Franco no concordaban con las de los Aliados.

Franco habia partido de una serie de presupuestos que, en su opinión, se harían realidad con el final de la contienda; pero tales presupuestos no llegaron a efecto. Se equivocó al creer que la actitud moralizante de los Aliados durante la guerra no era más que un producto del apasionamiento bélico, y que se terminaría cuando se aplacara tal apasionamiento. Franco estaba seguro de que después de la guerra volveria a reinar en la política internacional el pragmatismo y el "sano egoísmo" de las naciones. Pero el mundo de las relaciones internacionales a partir de 1945 no se regiria ya únicamente por los conceptos de la política de gabinete de los siglos precedentes, sino que, de ahora en adelante, la opinión pública sería un factor decisivo en el momento de adoptar una actitud a nivel de política internacional. Por otra parte, la imagen, ampliamente divulgada, de Franco como líder fascista dificultaría de forma notable una política respecto de su persona. La gran esperanza del régimen, de que España en 1945 sería tenida en consideración debido a su importancia estratégica, no se cumpliría.

Y si acaso pudiera argumentarse que Franco sí tuvo razón al predecir el enfrentamiento que tendría lugar después de la guerra entre Occidente y la Unión Soviética, habia de tenerse en cuenta al mismo tiempo que ser visceralmente anticomunista no era el principal requisito para entrar a formar parte del bloque defensivo de Occidente. Finalmente, el Estado franquista no sería aceptado en la Organización de las Naciones Unidas y no disfrutaría de las ayudas del Plan Marshall. De poco había servido a Franco citar una y otra vez el discurso de Churchill de mayo de 1944 y exigir su cumplimiento.

Franco, y con él amplios sectores del régimen, admiraban a Alemania y querian asegurarse su amistad incluso después de la guerra. $Y$ aunque todas las naciones abandonaran a Alemania, España no quiso en ningún caso hacer otro tanto. Franco quiso distinguirse como el último 
amigo inquebrantable de Alemania, y ser de nuevo el primer amigo de la Alemania de la postguerra. Un informe redactado por Vidal a mediados de octubre de 1944 expresa sin lugar a dudas el sentir de un amplio sector del régimen: «No se destruye tan fácilmente a un pueblo de más de 70 millones de almas, aunque no tuviese las cualidades del alemán. La comunidad alemana es una realidad geográfica y geopolítica. Fraccionada o soberana está aquí, en el centro de Europa, ocupando el puesto marcado por un destino secular, y no se ve cómo han de poder unos enemigos triunfantes suprimir o siquiera sojuzgar a una raza tan fecunda, prolífera, industriosa y audaz, logrando ahora lo que no lograron en el curso de los siglos Isabel, Luis XIV, María Teresa o Napoleón (...). En el juego de esas fuerzas y elementos que actúan en sentido diverso y aun opuesto a veces, Alemania será siempre uno de los más importantes con que habrá que contar inevitablemente. Si tanto han dado que hacer las minorias étnicas en países soberanos en el curso de los tiempos, júzguese la quimera que supone querer suprimir de un soplo a un pueblo tan compacto como el alemán» ${ }^{57}$.

Nunca se le ocurrió a Franco que Alemania desaparecería del mapa político por mucho tiempo. Y lo único que finalmente lograría aferrándose a la amistad con Alemania fue excluirse a sí mismo del orden mundial de postguerra. La fórmula de Lequerica para vencer la insistente presión del exterior no bastaria para neutralizarla: «Mantengamos pues una impasible actitud de defensa del orden español, de las bases populares y justicieras de nuestra vida interior y de la autoridad del General Franco, que todo el resto, como el reino de Dios y su justicia, seguramente vendrán de añadidura" ${ }^{58}$. Pero una cosa sí que logró Franco con esa fórmula: mantenerse en el poder y asegurar la continuidad de su régimen. 